\title{
Gamma-hydroxybutyrate (GHB), an unusual cause of high anion gap metabolic acidosis
}

Laurence Carlier, $\mathrm{MD}^{*}$; Vincent Van Belleghem, $\mathrm{MD}^{*}{ }^{\dagger} ;$ Kathleen Croes, PharmD, $\mathrm{PhD}^{\S}$;

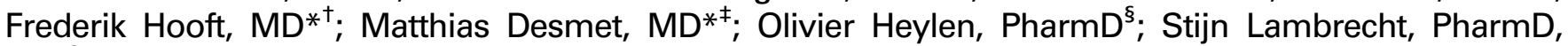
$\mathrm{PhD}^{\S}$; Stefaan Carlier, $\mathrm{MD}^{*}$

\section{ABSTRACT}

The causes of high anion gap metabolic acidosis (HAGMA) are well described in the literature. However, sometimes more frequent causes of HAGMA cannot explain its occurrence.

In the case of HAGMA and severe neurological depression in the absence of other causes of HAGMA, clinicians should consider an intoxication with gamma-hydroxybutyrate $(\mathrm{GHB})$ as a possible cause.

GHB is endogenous to the mammalian central nervous system (CNS). Synthetic GHB was initially used as an anesthetic but is now only licensed for medical use in a limited number of indications such as the treatment of narcolepsy. Because of its euphoric effects, it became popular for recreational use under the street names: Liquid Ecstasy, Georgia Home Boy, and Liquid G.

We describe the clinical case of a patient who suffered from severe neurological depression and HAGMA.

\section{RÉSUMÉ}

Les causes de l'acidose métabolique à trou anionique élevé (AMTAE) sont bien présentées dans la documentation médicale. Toutefois, il arrive que des causes plus fréquentes d'AMTAE ne peuvent expliquer ce trouble.

Dans les cas d'AMTAE et de dépression neurologique grave en l'absence d'autres facteurs étiologiques, les cliniciens devraient envisager la possibilité d'intoxication par le gammahydroxybutyrate (GHB).

Le GHB est une substance endogène du système nerveux central des mammifères. Quant au GHB de synthèse, il était utilisé au début comme anesthésique, mais son emploi à des fins médicales n'est autorisé maintenant que dans un petit nombre d'indications telles que le traitement de la narcolepsie. Enfin, l'utilisation à des fins récréatives du GHB, communément appelé « ecstasy liquide », « Georgia Home boy » ou « Liquid G », a gagné beaucoup de terrain en raison de ses effets euphorisants.

Sera exposé ici un cas clinique de dépression neurologique grave, accompagnée d'une acidose métabolique à trou anionique élevé.

Keywords: gamma-hydroxybutyrate, high anion gap

metabolic acidosis, neurological depression

\section{CASE REPORT}

A 54-year-old male was found in his car near his house and was admitted in the emergency department.
The patient was seen by his son shortly before he left and he seemed to be fine at that moment. The patient had a history of alcohol abuse. Except for a laminectomy and arterial hypertension, the patient had no medical history. His home medication was losartan and a pain killer when necessary. He had no known allergies.

At the moment that he was found, he was unresponsive to verbal command and painful stimuli with a Glasgow Coma Scale of 3/15. His heart rate and blood pressure were normal, and clinical examination did not reveal major injury. To protect the airway, the trachea was immediately intubated on the spot, and the patient was ventilated. To rule out severe traumatic brain injury, a CT scan was performed, which did not reveal posttraumatic injury. A 12-lead electrocardiogram showed no signs of ischemia or rhythm disturbances.

Peripheral blood count and liver biochemistry were within normal limits. The patient had an estimated glomerular filtration rate above $1.50 \mathrm{ml} / \mathrm{s} / \mathrm{m}^{2}$, which was normal. Because serum prolactin levels were slightly elevated $(2146.55 \mathrm{pmol} / \mathrm{L}$, normal values $[\mathrm{N}]: \quad 165-$ $1010 \mathrm{pmol} / \mathrm{L})$, an electroencephalogram was performed. There were no signs of seizure activity. Lactate was within normal range $(1.67 \mathrm{mmol} / \mathrm{L}, \mathrm{N}: 0.50-2.20)$, as well as glucose $(6.16 \mathrm{mmol} / \mathrm{L}, \mathrm{N}: 3.9-6.6 \mathrm{mmol} / \mathrm{L})$. Ethanol on this sample was slightly elevated $(10.2 \mathrm{mmol} / \mathrm{L}, \mathrm{N}$ : $<2.17 \mathrm{mmol} / \mathrm{L})$. The serum osmolality was $287 \mathrm{mOsm} / \mathrm{kg}$ (N: $280-300 \mathrm{mSsm} / \mathrm{kg}$ ) and serum creatinine was 83.1 micromol/L (N: 51.3-107.0 micromol/L).

An arterial blood gas analysis revealed the following: $\mathrm{pH} 7.07$ (N: 7.35-7.45), bicarbonate $12.6(\mathrm{~N}: ; 22.0-$ $26.0 \mathrm{mmol} / \mathrm{L})$, sodium 136 ( $\mathrm{N}: \quad 136-145 \mathrm{mmol} / \mathrm{L}$ ),

From the *Department of Anesthesiology, †Department of Emergency Medicine, and ¥Department of Intensive Care, AZ Groeninge, Kortrijk, Belgium; and §Clinical laboratory and toxicology, AZ Groeninge, Kortrijk, Belgium.

Correspondence to: Laurence Carlier, AZ Groeninge, Pater Damiaanstraat 98500 Kortrijk, Belgium; Email: Laurence.carlier@student.kuleuven.be 
potassium $4.11(\mathrm{~N}: 3.50-5.10 \mathrm{mmol} / \mathrm{L})$, chloride 95.2 $(\mathrm{N}: \quad 98.0-107 \mathrm{mmol} / \mathrm{L})$, and $\mathrm{pCO} 244.2(\mathrm{~N}: 35.0-$ $45.0 \mathrm{~mm} \mathrm{Hg}$ ), indicating a HAGMA with an anion gap of $28.2 \mathrm{mmol} / \mathrm{L}(\mathrm{N}: 11.0-21 \mathrm{mmol} / \mathrm{L})$.

Carbon monoxide (CO) intoxication was unlikely because the patient's car was parked outside before leaving and was ruled out by a normal $\mathrm{CO}$ hemoglobin level (3.7\%) (N: $<5$ to $6 \%$ TIETZ) upon arrival at the hospital. An arterial blood gas analysis less than 12 hours after the first arterial blood gas analysis was normal (Table 1).

Because ketoacidosis is a well-known cause of HAGMA, urine was tested for ketones and glycose. The test was the Roche Combur ${ }^{10}$ Test M strip, and it was negative.

Subsequent toxicological screening of serum for acetaminophen, salicylate, benzodiazepines, barbiturates, and tricyclic antidepressants was negative. Urine was screened for barbiturates, benzodiazepines, acetaminophen, tricyclic antidepressants, (meth) amphetamine, cocaine, opiates, and methadone and was found negative as well.

The analysis of (toxic) alcohols was performed by headspace gas chromatography with flame ionization detection (HS-GC-FID) and allowed simultaneous detection of methanol, ethanol, n-propanol, isopropanol, and acetone. The analysis of glycols (ethylene glycol and propylene glycol) was performed by GC-FID. Serum concentrations of acetone, all alcohols, and glycols tested were $<0.86 \mathrm{mmol} / \mathrm{L}$ at this moment (Tables 2 and 3 ).

On the basis of the laboratory results of blood and urine samples and clinical examination, common causes of HAGMA (ethylene and propylene glycol, lactate, methanol, salicylate, renal failure, and ketoacidosis) were ruled out (see Tables 2 and 3).

\begin{tabular}{|c|c|c|c|}
\hline \multicolumn{4}{|c|}{ Arterial blood gas analysis } \\
\hline Time & 1850 (day 1) & 2341 (day 1) & 0535 (day 2) \\
\hline $\mathrm{pH}$ & 7.07 & 7.27 & 7.37 \\
\hline $\mathrm{pCO} 2$ & $44.2 \mathrm{~mm} \mathrm{Hg}$ & $36.8 \mathrm{~mm} \mathrm{Hg}$ & $34.5 \mathrm{~mm} \mathrm{Hg}$ \\
\hline pO2 & $155.5 \mathrm{~mm} \mathrm{Hg}$ & $88.2 \mathrm{~mm} \mathrm{Hg}$ & $137.2 \mathrm{~mm} \mathrm{Hg}$ \\
\hline O2-saturation & $98.2 \%$ & $96 \%$ & $98.9 \%$ \\
\hline $\mathrm{Co} \mathrm{Hb}$ & $3.7 \%$ & - & - \\
\hline Bicarbonate & $12.6 \mathrm{mmol} / \mathrm{L}$ & $16.6 \mathrm{mmol} / \mathrm{L}$ & $19.7 \mathrm{mmol} / \mathrm{L}$ \\
\hline Base excess & $-17 \mathrm{mmol} / \mathrm{L}$ & $-9.5 \mathrm{mmol} / \mathrm{L}$ & $-4.8 \mathrm{mmol} / \mathrm{L}$ \\
\hline Glucose & $111 \mathrm{mg} / \mathrm{dl}$ & $123 \mathrm{mg} / \mathrm{dl}$ & 115 mg/dl \\
\hline Lactate & $1.9 \mathrm{mmol} / \mathrm{L}$ & $2.3 \mathrm{mmol} / \mathrm{L}$ & $1.7 \mathrm{mmol} / \mathrm{L}$ \\
\hline
\end{tabular}

The diagnosis of a severe GHB intoxication causing HAGMA was established after gas chromatographicmass spectrometric analysis (GHB serum: $10.64 \mathrm{mmol} / \mathrm{L}$, GHB urine $33.53 \mathrm{mmol} / \mathrm{L}$ ). The sample tested for GHB was taken 210 minutes after the first blood gas. A plasma level of $0.048 \mathrm{mmol} / \mathrm{L}$ and a urine level of $0.096 \mathrm{mmol} / \mathrm{L}$ was used as a cut-off concentration of normal endogenous GHB concentrations.

Supportive therapy with sedation, ventilation, fluid replacement, and bicarbonate was given. The patient fully recovered after 17 hours and was discharged to the ward on the following day. Questioning of the patient and of his son confirmed the hypothesis that the patient accidentally ingested GHB. He thought the bottle that he found under the bed of his son was a bottle of gin. The bottle was not submitted for analysis.

\begin{tabular}{|c|c|c|}
\hline Toxicology on blood & Results & Methods \\
\hline Ethanol & $10.2 \mathrm{mmol} / \mathrm{L}$ & Roche enzymatic assay \\
\hline $\begin{array}{l}\text { Tricyclic } \\
\text { antidepressants }\end{array}$ & Negative & $\begin{array}{l}\text { Microgenics DRI } \\
\text { immunoassay }\end{array}$ \\
\hline Benzodiazepines & Negative & Roche immunoassay \\
\hline Acetaminophen & $\begin{array}{l}<13.24 \\
\quad \text { micromol/L }\end{array}$ & Roche enzymatic assay \\
\hline Salicylates & $<2 \mathrm{mg} / \mathrm{L}$ & Roche enzymatic assay \\
\hline Barbiturates & Negative & Roche immunoassay \\
\hline Methanol & $<1.56 \mathrm{mmol} / \mathrm{L}$ & HS-GC-FID \\
\hline Ethylene glycol & $\begin{array}{l}<805 \\
\text { micromol/L }\end{array}$ & GC-FID \\
\hline
\end{tabular}

Table 3. Toxicology results obtained on urine

\begin{tabular}{|c|c|c|}
\hline Parameter & Results & Methods \\
\hline $\begin{array}{l}\text { Tricyclic } \\
\text { antidepressants }\end{array}$ & Negative & $\begin{array}{c}\text { Microgenics DRI } \\
\text { immunoassay }\end{array}$ \\
\hline Benzodiazepines & Negative & Roche immunoassay \\
\hline Opioids & Negative & Roche immunoassay \\
\hline Phenylalkylamine & Negative & Roche immunoassay \\
\hline Cocaine & Negative & Roche immunoassay \\
\hline Methadone & Negative & Roche immunoassay \\
\hline Salicylates & Negative & Colorimetric assay \\
\hline Barbiturates & Negative & Roche immunoassay \\
\hline Acetaminophen & $\begin{array}{c}\text { Negative }(<13.24 \\
\text { micromol/L) }\end{array}$ & $\begin{array}{l}\text { Roche enzymatic } \\
\text { assay }\end{array}$ \\
\hline Creatinine & 530.4 micromol/L & $\begin{array}{l}\text { Roche colorimetric } \\
\text { assay }\end{array}$ \\
\hline
\end{tabular}




\section{DISCUSSION}

GHB is endogenous to the mammalian CNS, but normal endogenous blood and urine concentrations are low $(<0.096 \mathrm{mmol} / \mathrm{L}){ }^{1,2}$ Interpretation of blood levels can be false due to collection tube additives and storage temperature, which can affect the GHB levels. The optimal specimen for testing for the presence of GHB is a urine sample. It should be taken in consideration that urine concentrations after ingestion of $\mathrm{GHB}$ vary widely. ${ }^{1}$ Gas chromatographic-mass spectrometric analysis is the best way to confirm the presence of GHB in blood or urine. GHB is rapidly absorbed and eliminated from the body. The elimination of biological half-life is $30-50$ minutes. Because of its fast elimination, GHB can usually not be detected in plasma more than 250 minutes after ingestion. ${ }^{2}$

The concentration of GHB in urine is comparable with the concentration in the blood during the time that urine was produced in the kidney and stored in the bladder. This can explain why toxicology for GHB can be positive in urine and negative in blood. ${ }^{2}$

Gamma-hydroxybutyric aciduria is the only known metabolic disease with high endogenous GHB concentrations. Synthetic GHB was initially used as an anesthetic but is now only licensed for medical use in a limited number of indications such as the treatment of narcolepsy. ${ }^{3}$ Because of its euphoric effects, it became popular for recreational use under the street name, Liquid Ecstasy. Other popular names for GHB are cherry meth, growth hormone booster, scoop, Liquid X, Liquid G, and Georgia Home Boy. GHB as such is a white crystalline powder but is most frequently vended as a solution. These liquid forms have widely variable GHB concentrations. It is also used as a sleep aid and is ingested chronically to increase lean body mass by body

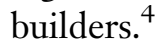

The presentation of a GHB intoxication is well described in the literature. Low doses have a relaxant effect similar to that of alcohol, and higher doses will lead to severe CNS depression. The drug has a steep doseresponse curve with a small therapeutic window leading to an abrupt decrease in the level of consciousness. The absorption of GHB is fast, and the time to reach the maximum plasma level depends on the dose that is administered. It takes approximately 30 to 60 minutes to reach peak plasma levels after ingestion of $50 \mathrm{mg} / \mathrm{kg}^{4}$

The clinical presentation of a GHB intoxication can be obscured due to concomitant drug use. In a case series

\begin{tabular}{|ll|}
\hline Table 4. Dose-related symptoms of GHB \\
\hline Dose & Symptoms \\
\hline $10 \mathrm{mg} / \mathrm{kg}$ & Short-term amnesia, hypotonia \\
$20-30 \mathrm{mg} / \mathrm{kg}$ & Drowsiness, sleep \\
$50-70 \mathrm{mg} / \mathrm{kg}$ & Profound hypnosis, deep coma \\
\hline
\end{tabular}

\begin{tabular}{|ll|}
$\begin{array}{l}\text { Table 5. GHB peak plasma concentration and its clinical } \\
\text { effects }\end{array}$ \\
\hline GHB concentration (mmol/L) & Clinical effects \\
\hline $0-0.95$ & Awake \\
$0.61-1.56$ & Light sleep (occasional eye opening) \\
$1.45-2.81$ & Medium sleep (blinking) \\
$2.34-3.79$ & Deep sleep (no response to stimuli) \\
\hline GHB $=$ gamma-hydroxybutyrate. & \\
\hline
\end{tabular}

study, Galicia et al. demonstrated that $76 \%$ of the patients combined GHB with other drugs such as alcohol, cocaine, ketamine, cannabis, and so forth. This multiple drug abuse leads to a more severe clinical presentation and will increase the need of more invasive therapy. ${ }^{5}$

Not only CNS symptoms can be present in a GHB intoxication, but also common other symptoms, including vomiting, urinary and fecal incontinence, bradycardia, hypoventilation, miosis, mydriasis, and hypothermia. The symptoms depend on the ingested dose (Tables 4 and 5).

GHB is a physiological metabolite of gammaaminobutyric acid, which plays a role in the control mechanism of the pituitary hormones. The release of dopamine, which is a prolactin-release inhibiting factor, is blocked by GHB. As a consequence, GHB induces a release of prolactin. ${ }^{6}$ Prolactin can also be raised after a generalized tonic-clonic seizure and after a nonepileptic seizure as well as after a syncope, indicating that increased prolactin levels cannot be used to differentiate between seizures, syncope, and GHB intoxication. $^{7,8}$ Patients who suffered from a generalized tonic-clonic insult have a marked elevation of lactate and often suffer from lactate acidosis. ${ }^{\text {? }}$

The treatment of GHB intoxications is supportive because no antidote is available. In our patient, the $\mathrm{pH}$ was corrected with bicarbonate infusions. In one other case report, dialysis was used to correct the $\mathrm{pH}$ because bicarbonate therapy was unsuccessful. ${ }^{10}$

HAGMA could also be caused by the presence of methanol or ethylene glycol metabolites, while the parent compound was fully metabolized. However, given the toxicity of methanol and ethylene glycol, 
full recovery of the patient without sequelae would be unlikely. An intoxication with propylene glycol, a solvent for intravenous drugs, is very rare and is unlikely to provoke a coma. ${ }^{11}$

HAGMA after GHB intoxication is rarely reported in the literature. To our knowledge, this is only the second case described in the literature. The first case was a gamma-butyrolactone (GBL) intoxication with a high anion gap and osmolal gap. However, because GBL is readily converted to GHB in the body, only GHB was detected, in this case. ${ }^{10}$

The pKa of GHB is 4.7 , meaning that in physiological conditions $99 \%$ of GHB is ionized, leading to excess anions causing HAGMA. ${ }^{10}$ Textbooks and clinical teaching do not incorporate GHB as a possible cause of HAGMA. Mehta et al. suggested a 21st century mnemonic for HAGMA: GOLDMARK (glycols, oxoproline, L-lactate, D-lactate, methanol, aspirin, renal failure, ketoacidosis). ${ }^{12} \mathrm{We}$ suggest that "G" should stand not only for glycols but also for GHB.

\section{CONCLUSION}

In the case of HAGMA and severe neurological depression in the absence of other causes of HAGMA, clinicians should consider an intoxication with GHB as a possible cause.

Competing interests: None declared.

\section{REFERENCES}

1. Haller C, Thai D, Jacob P, et al. GHB urine concentrations after single-dose administration in Humans. 7 Anal Toxicol 2006;30:360-4.

2. Busardo FP, Jones AW. GHB pharmacology and toxicology: acute intoxication, concentrations in blood and urine in forensic cases and treatment of the withdrawal syndrome. Curr Neuropharmacol 2015;13:47-70.

3. Corkery J, Loi B, Claridge H, et al. GHB, GBL, 1,4-BD: a literature review with a focus on UK fatalities related to non-medical use. Neurosci Biobehav Rev 2015;53:52-78.

4. Benzer T, Cameron S, Scott Russi C, et al. Gammahydroxybutyrate toxicity. Medscape; 2015. Available at: http://emedicine.medscape.com/article/820531-overview.

5. Galicia M, Nogue S, Mir O. Liquid ecstasy intoxication: clinical features of 505 consecutive emergency department patients. Emerg Med 7 2011;28:462-6.

6. Takahara J, Yunoki S, Yakushiji W, et al. Stimulatory effects of gamma-hydroxybutyric acid on growth hormone and prolactin release in humans. 7 Clin Endocrinol Metab 1977;44:1014-7.

7. Vukmir RB. Does serum prolactin indicate the presence of seizure in the emergency department patient? 7 Neurol 2004;251:736-9.

8. Chen DK, So YT, Fisher RS. Use of serum prolactin in diagnosing epileptic seizures. Neurology 2005;65:668-75.

9. Baba R, Zwaal JW. Severe metabolic acidosis after a single tonic-clonic seizure. Anaesthesia 2005;60:623-4.

10. Heytens L, Neels H, Van Regenmortel N, et al. Near-fatal persistent anion- and osmolal-gap acidosis due to massive gamma-butyrolactone/ethanol intoxication: a case report. Ann Clin Biochem 2015;52:283-7.

11. Kraut JA, Kurtz I. Toxic alcohol ingestions: clinical features, diagnosis and management. Clin 7 Am Soc Nephrol 2008;3:208-5.

12. Mehta AN, Emmett JB, Emmett M. GOLD MARK: an anion gap mnemonic for the 21st century. Lancet 2008; 372(9642):892. 